\title{
The Application of Production-Oriented Approach in General English
}

\author{
Jiang Wang
}

(Wuhan Donghu University, Wuhan, 430212)

\section{Keywords: General English; Production-oriented approach; Applied research}

\begin{abstract}
The "production-oriented approach" theory system is one of the important parts of the foreign language teaching theory with Chinese characteristics. Its core is "three doctrines", "three hypotheses" and "three stages". Its aim is to promote the realization of the goal of foreign language classroom teaching and the occurrence of effective learning. The theoretical system of "Production-oriented approach" and its practical research results are analyzed in this paper, and the practicality and necessity for using this approach in general English classes is discussed. It is hoped that teaching efficiency and quality can be improved by this approach.
\end{abstract}

\section{Introduction}

As a required course, the importance of general English is self-evident. In a dazzling array of English language teaching theories, the production-oriented approach (POA) has come to the fore with its complete theoretical system. The production-oriented teaching approach balances knowledge input and production as the ultimate goal of learning, and it has also been recognized and welcomed by teachers and students. This paper analyzes the application of production-oriented teaching approach in the general English teaching in details according to the three concepts of production-oriented teaching approach and the teacher-mediated teaching process, taking the production-oriented teaching method as the theoretical system, and trying to provide practical evidence for getting into the general English for the POA. Case references are provided for general students to improve English learning production and for the teachers to improve current teaching quality, and empirical literature for English language teaching researchers on how POA affects general English teaching.

\section{Research on the Background of Production-Oriented Approach}

The POA theoretical system mainly includes teaching philosophy, teaching assumptions and teacher-mediated teaching process, where the teaching philosophy mainly refers to the "three doctrines" that is, the learning center theory, the theory of learning and application in one and the whole person education; the teaching hypothesis includes the three hypotheses of product-motivating, input-enabling and selective learning; and the teaching flow includes motivating, enabling and assessing. The POA theoretical system has several bright points that are worthy of being referred by the colleagues in the industry: the first is that the "production-oriented approach" targets middle-to-high-level foreign language learners; the other refers to the main difference between "production" and "product" is that the former not only emphasizes the process of production (producing) but also emphasizes the outcome (product), including speaking, writing, interpretation, and translation, but the latter only refers to speaking and writing. Thirdly, POA proposes the "learning center theory" at the first time and emphasizes "all activities in classroom teaching must serve the occurrence of effective learning". It challenges the popular "student-centered concept" at home and abroad. POA teaching theoretical system is shown as Fig.1 


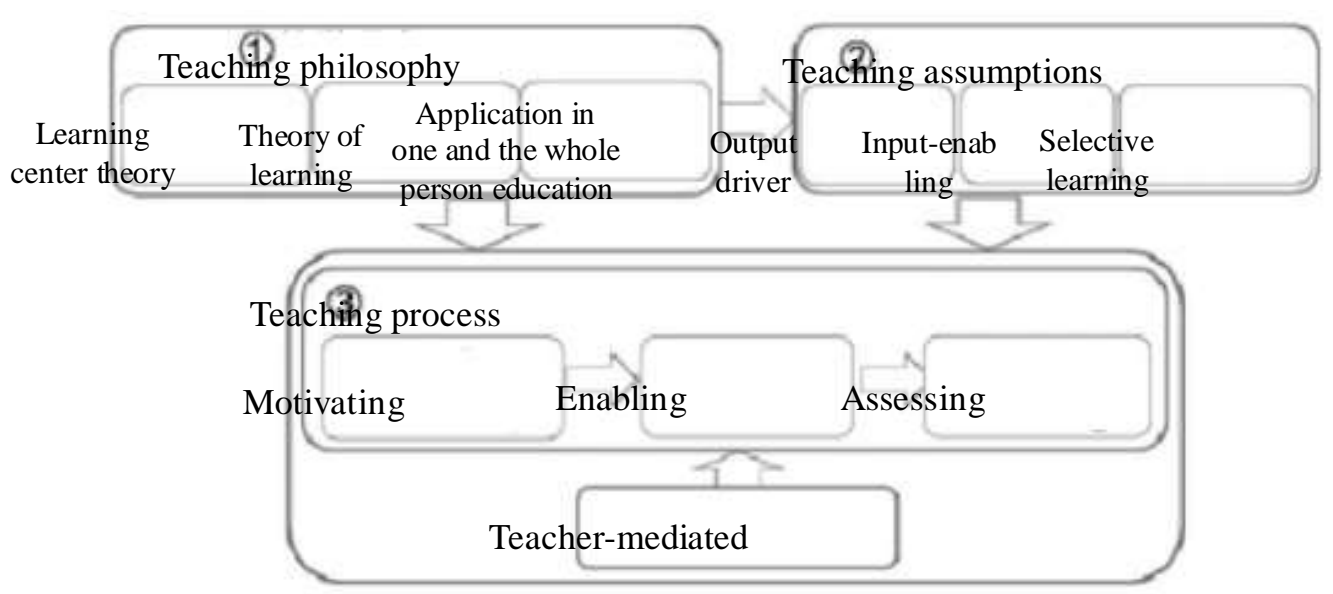

(1) Teaching philosophy: learning center theory, the theory of learning and application in one and the whole person education

(2) Teaching assumption: product-motivating, input-enabling and selective learning

(3) Teaching process: motivating, enabling, assessing. teacher-mediated

Fig.1 POA teaching theoretical system

The concept of POA theoretical system is that the ultimate goal of English knowledge input is efficient production. Therefore, English teaching must be "complete and consistent". The learning center theory requires that English learning focuses on the learning process itself, and the theory of learning and application in one requires the learner to "apply their knowledge" and integrate knowledge input and production; the whole-person learning theory requires the learner to focus on the instrumentality and humanity of English learning. Only by integrating these three teaching concepts with each other and introducing them into the process of general English teaching practice, can we form a relatively complete systematic integrated teaching philosophy. The production of POA teaching is motivated by input, allowing students to choose their own learning, and optimizing the effectiveness of English learning with the help of teacher-mediated assessment.

\section{POA Makes Up for the Current General English Teaching Theory and Practice Defects}

\section{Deflected teaching center}

The "learning center" and "teacher center" all deviates from the "center" of English teaching. The POA believes that the center of teaching is "effective learning". Therefore, its theory "learning center" is to promote effective learning as the ultimate goal, taking into account the role of students and teachers. At this point, it is closer to the essence of English education. In the general English class, teachers play multiple roles such as instruction, planning, control, promotion, assistance, and evaluation of teaching. Students participate in classroom activities of various forms, such as group discussions, and completing teaching tasks and achieving teaching goals under highly effective cooperation with teachers. In this way, teachers and students not only highlight their main role in the classroom, but also have effective and full use of class hours.

1. Reduced role of teaching material

In the current general English learning, there is still a large number of teachers who follow the teaching philosophy of traditional "book center theory". In the current English teaching classroom, English teachers generally teach according to English textbooks in a step-by-step manner, perform detailed reading analysis and matched text exercises after class. Needless to say, there is an obvious flaw in this teaching method, that is, it is difficult to cultivate students' English application skills by taking textbooks as the only tool for English teaching. In other words, the "textbook-centered" teaching model, which ignores the combination of input and production of teaching, will lead to the failure of transforming knowledge input into effective production in long time, and students will be trapped in the rigid state of English learning. The concept of "integrating learning and application in one" in POA teaching breaks the "backwater" of general English teaching and advocates the integration of "learning" and "use" in general English classroom teaching to overcome the 
embarrassing phenomenon of "dumb English”.

\section{The Application of "Production-Oriented Approach" in General English}

The teacher-mediated POA teaching process mainly includes three stages: motivating, enabling and assessing. At different stages, teachers need to play different roles, focus on different contents and achieve different goals.

During the motivating phase, teachers can introduce students with PPT projection, video playback, and micro lessons. That is, the teaching steps can be intuitively and vividly presented to students through multimedia devices such as videos, audios, animations, and pictures, which are essentially different from the traditional teaching leading. The characteristic of the POA motivating is that it can enable students to enter the three-dimensional classroom without barriers, and make good preparations for promoting the completion of the teaching task in the second phase.

Under the premise of motivating stage, teachers follow the concept of "Student center". Students are divided into groups on the spot. Brainstorming is conducted around a topic to let students brainstorm and collaborate to complete teaching tasks. In this process, students can learn from each other through participation, interaction and mutual enlightenment, and continue to build and improve their own knowledge system.

After the motivating and enabling phase, students have not yet completed their teaching tasks and have not achieved the maximum level of knowledge production. Therefore, teacher mediation is needed to assess the students' task completion. The assessment phase can be divided into: in-class assessment and extracurricular assessment. In the assessment part of the lesson, teacher makes full use of the remaining hours after the task, allowing students to participate in on-site exercises and evaluate the students' training results in class. In the extracurricular assessment, teachers use mobile devices such as mobile phones, PCs, and Pads as assistant assessment tools to conduct online assessment for students' completion of extra-curricular tasks. The restrictions of time and space on English teaching can be broken through, and English learning should run through the class.

\section{Conclusion}

The POA teaching theory system has so far required a large number of teaching attempts in the practice of general English teaching, and it is still in a period of perfect development. Therefore, the research of this paper is a good starting point. We hope that in the near future, this kind of effective teaching approach can be truly applied to the general English teaching class, realizing its due value. The research done by the author still must be further improved and implemented. Only through continuous practice can we discover the utility of POA theory in English teaching and the theoretical guidance value of it. In China, where English is the second language, English teaching theory emerges in an endless stream, which requires English teaching and research and workers to constantly improve their theoretical foundation and academic level, and find the most appropriate practical teaching approaches in English teaching practice.

\section{Acknowledgement}

Project funding: The subject of educational teaching reform in Wuhan Donghu University (No.170025)

\section{References}

[1] Takahashi, Reiko. English as a lingua franca in a Japanese context : an analysis of ELF-oriented features in teaching materials and the attitudes of Japanese teachers and learners of English to ELF-oriented materials[J]. University of Edinburgh, 2011.

[2] Tian X. Success-Oriented Education: Target Realization: Teaching Materials Based on Web Resource[J]. 2011, 216(9):26-30. 
[3] Min D. Explorations on Development of Campus-oriented Public English Teaching Materials in High Vocational Colleges[J]. Journal of Xiangfan Vocational \& Technical College, 2011.

[4] Guo R. Discussion of Application-oriented Materials Professional English Teaching Reform[J]. Guide of Science \& Education, 2017.

[5] Wang L Y. A Study of Career Orientation of English Teaching Material Text of Higher Vocational College[J]. Vocational \& Technical Education, 2014.

[6] Li-Lu H E, Ying L I, Kai-Yi T U. The Application of Authentic Materials in Teaching Skill-oriented Course for English Majors__An Empirical Study on the Teachers' and Students' Attitude in English Departments of Independent College[J]. Overseas English, 2015.

[7] Wang X, Dong X, Chaohong M A, et al. The Research and Exploration of Application-oriented University's Basic Chemical Teaching Material[J]. Journal of Jilin Agricultural Science \& Technology University, 2014.

[8] Daohai L I, Department G T. On Course Characteristics and Teaching Method of General Education in Application-oriented Universities —A Case Study on "Chinese Classic Literature Appreciation'[J]. Journal of Educational Institute of Jilin Province, 2016.

[9] Wen L. Research on the Construction of College Teaching Materials and the Cultivation of Application-Oriented Talents[J]. Science Education Article Collects, 2013.

[10] Zheng X. Teaching material construction of science and engineering for application-oriented universities[J]. China Modern Educational Equipment, 2014.

[11] Dai P F. Discussion on Reform of Curriculum Teaching of Calulation Method in Application-oriented Undergraduate[J]. Journal of Lanzhou University of Arts \& Science, 2015.

[12] Chen X Y, Guan-Lin L I, Liu F C, et al. Construction of Teaching Material Oriented Engineering Education for Electrical Information Majors[J]. Journal of Electrical \& Electronic Education, 2016. 